\title{
Competitive Diffusion of Nuclear and Nonnuclear Energy in Korea*
}

\author{
In-Young Hwang** and J. Hun Park***
}

\begin{abstract}
This study explains the competitive diffusion of nuclear energy and nonnuclear energy, adopting the Lotka-Volterra model of nonlinear dynamics to do so. In this paper, the competitive relationship in the energy diffusion process is treated as a competitive ecosystem in which nuclear energy as an emerging species competes with existing nonnuclear energy. We analyze installed capacity data of each energy source from 1978 to 2012. Using estimated Lotka-Volterra models, we investigate what kind of competitive relationship obtained between nuclear and nonnuclear power in the energy policies of every South Korean government from 1982 to 2012. The result shows that mutualism has largely characterized energy diffusion in Korea. That is, nuclear energy and nonnuclear energy stood in a win-win relationship to each other most of the time, promoting the proliferation of each other in the diffusion process. Between 1988 and 1991, in 1997, and then again 2008, the relationship between the two was a predatorprey one: nuclear energy as a predator inhibited the diffusion of nonnuclear energy as a prey in the diffusion process. This result implies the path dependency of the energy policy in Korea. Taking the current competitive environment as our cue, we forecast the future diffusion scenario using an equilibrium analysis and a numerical simulation. The forecast shows that the proportion of installed nuclear capacity in 2030 will reach to $23.8 \%$ of total energy sources, which is about $5 \%$ below the energy policy goal set by the Park Keun-hye government recently.
\end{abstract}

Keywords: energy diffusion, nuclear energy, Lotka-Volterra

\section{INTRODUCTION}

After the opening of Kori, the first commercial nuclear power plant, in 1978, nuclear energy rapidly emerged as the primary energy source in Korea. Although in the

\footnotetext{
* This work was supported by Seoul National University Foundation in 2014.

** In-Young Hwang is a master's student in the Graduate School of Public Administration at Seoul National University. E-mail: smarthiy@ naver.com.

*** J. Hun Park, corresponding author, is a professor in the Graduate School of Public Administration at Seoul National University. E-mail: dearpark@snu.ac.kr.
}

Manuscript received Jun 10, 2014; out for review Jun 20, 2014; review completed August 10, 2014; accepted August 13, 2014.

The Korean Journal of Policy Studies, Vol. 29, No. 2 (2014), pp. 1-20.

(C) 2014 by the GSPA, Seoul National University 
wake of the 1986 Chernobyl accident, the use of nuclear energy declined worldwide, in Korea nuclear energy consolidated its position as the main energy source. The rapid diffusion of nuclear energy in Korea was instigated by a worry that with the existing energy sources, it could be difficult for Korea to meet the new energy demand arising from the rapid economic growth that took place in the country during the 1970s and 1980s. Korea's nuclear energy policy was first implemented and then enhanced afterward under the strong leadership by consecutive military regimes. In the 1990s, however, after Korea underwent democratization and the local self-government system was implemented, citizens and residents who lived near nuclear reactors began voicing strong opposition the policy of expanding nuclear power. Therefore, it was no longer able to sustain a strong nuclear energy policy as before.

This study aims to explain competitive diffusion trends among various energy sources since the advent of nuclear energy in Korea. The nuclear energy option represents a strong alternative to and substitute for existing nonnuclear energy sources, so the diffusion process of nuclear energy can be described in the context of competitive relationships with other nonnuclear energy sources. However, the majority of previous studies have focused on qualitative issues pertaining to the institutions and agents that create nuclear energy policy (Lee, 2001; Yoon \& Bae, 2008; Jin, 2009), so these studies do not explore the competitive relationship among various energy sources.

As Epstein (1997) has pointed out, the qualitative behavior of society can be effectively analyzed using mathematical models. To explain the diffusion process of nuclear energy sources in terms of nonlinear dynamics and interactions between competing energy sources, this study adopts a mathematical model, so called Lotka-Volterra model (Lotka, 1925; Freedman, 1980; Hoppensteadt, 2006), which may compensate for the methodological weaknesses of existing qualitative studies. Lotka-Volterra equations, also known as the predator-prey equations, are effectively used to describe the dynamics of two competing species, one as a predator and the other as prey. This study treats the nuclear energy diffusion process as the propagation of a new emerging species in the ecosystem that competes with existing nonnuclear energy. Basically, with limited resources, stiff competition arises over expanding energy facilities, since it is a matter of selecting an appropriate energy option in the portfolio of various energy sources.

This study begins with a literature review of the Lotka-Volterra model in social science research. After explaining how we use the Lotka-Volterra model in our analysis, we test estimated models from our data. Then, based on estimated models, competitive relationships between nuclear energy and nonnuclear energy are analyzed by year and government. After estimating equilibrium points in the current competitive relationship, 
the future diffusion scenario is forecasted. Results are summarized with implications and directions for future research.

\section{LITERATURE REVIEW}

\section{Framework for Energy Diffusion}

Typical diffusion processes begin gradually, go through a period of rapid expansion, and finally reach a saturation stage. Most diffusion models such as the Lotka-Volterra, the Gompertz, and the Bass models are based on logistic growth equations and represent population growth as S-curve (Valle \& Furlan, 2014). Early studies on energy diffusion dealt mainly with the spread of epidemics. Marchetti (1981) conducted an initial study of dynamics of energy diffusion and successfully described long-range behavior of the energy market and its submarket using the logistic growth model. After Marchetti had shown that the growth of energy follows an S-curve, diffusion models began to be applied to the energy sector (Guidolin \& Guseo, 2012; Van der Heiden \& Strebel, 2012).

In an early study using a nuclear energy diffusion model to analyze the position of nuclear energy, Marchetti (1985) estimated the niche of nuclear energy using the Lotka-Volterra model, which is a competitive diffusion model of formal Darwinian biology. He considered various energy sources as species and used the biological concept of niche. In other words, his study was based on the concept of similarity between the diffusion of nuclear energy and the logistic growth of species until they fill a niche. As Duan, Zhu, and Fan (2014) have pointed out, most diffusion models of nuclear energy borrow the model of mathematical epidemiology.

Regarding renewable energy diffusion, Koo, Lee, and Kim (2014) have observed that related research has focused on forecasting the pattern of energy diffusion and that the logistic model and its variants such as Lotka-Volterra, the Gompertz, and the Bass models are widely used for forecasting gradual growth to a specific value. The need for energy forecasting using diffusion models has also been addressed in several studies. Pandey (2002) argued that the mathematical modeling used to deal with the mediumand long-term uncertainty of energy forecasting is likewise critically useful in evaluating the robustness of energy policy. Hwang (2011) underlined the necessity of building dynamic models to develop predictable scenarios for energy diffusion. Table 1 summarizes studies on diffusion models for energy forecasting. 
Table 1. Studies on Diffusion Models for Energy Forecasting

\begin{tabular}{l|l}
\hline \multicolumn{1}{c|}{ Model } & \multicolumn{1}{c}{ Studies } \\
\hline Lotka-Volterra & $\begin{array}{l}\text { Marchetti (1985) (nuclear) } \\
\text { Koo et al. (2014) (renewables) } \\
\text { Duan et al.(2014) (renewables) }\end{array}$ \\
\hline Bass & Hwang et al. (2005) (renewables) \\
\hline GBM & $\begin{array}{l}\text { Valle \& Furlan (2014) (nuclear) } \\
\text { (generalized Bass model) }\end{array}$ \\
\hline GGMidolin \& Mortarino (2010) (renewables) \\
Valle \& Furlan (2011) (renewables)
\end{tabular}

\section{Competitiveness Among Energy Options}

As is typically the case, economic competition is an important decision factor in electricity generation. Toth and Rogner (2006) showed that nuclear energy and fossil fuel energy compete against each other. They cited costs, cleanness, safety, dependability, and convenience as core elements of energy competitiveness. They noted that the competition occurs in the electricity generating market in particular and that in the wake of the 1973 oil crisis, nuclear energy has become the most powerful rival to fossil fuels, diversifying and stabilizing Korea's national energy supply. In other words, nuclear energy has expanded its share since 1973, and it seems clear it will play a most important part in the energy portfolio in the future.

Adamantiades and Kessides (2009) cited low costs and short construction times as core elements of energy competitiveness. They argued that the cost reduction in plant operation following design modification and simplification greatly increased the competitiveness of nuclear energy. Choi et al. (2009) similarly argued that nuclear energy in Korea has maintained high cost competitiveness with respect to other energy sources in its energy portfolio, resulting in increased profits and a more stable financial status for the nuclear sector. Kessides (2010) likewise concluded that nuclear energy has a competitive advantage over fossil fuel energy because of its low price. Koplow (2011) claimed that the price factor is significant when making a decision about what form of energy to invest in out of the whole energy portfolio. Though various energy options exist, including renewable energy, Guidolin \& Guseo (2012) contended that competition has become more intense in the energy sector of many countries and that the nuclear energy option can eliminate all the uncertainties related to oil and natural gas supply.

Regarding negative sides of nuclear energy, Furlan et al. (2014) noted that the 
possibility of uranium 235 depletion and the rising cost of risk management are the main factors that affect the competitiveness of nuclear energy. They added that nuclear energy policy of leading energy consuming countries like United States and France was not affected or else only affected slightly by the Fukushima accident. They also claimed that price and depletion factors can be more powerful than political and social factors in the nuclear energy sector. Valle \& Furlan (2014) further argued that the most important issue for the future will be how achieve a balance between satisfying energy demands, on the one hand, and answering social, environmental, and political needs, on the other, in such a way as to allow for healthy social and economic progress.

\section{Lotka-Volterra Model}

The Lotka-Volterra model is basically a diffusion model for two different species that stand in a predator-prey relationship. Consequently, original research using the model was carried out mainly in the field of biology and epidemiology. In general, the model accounts for the phenomenon whereby the growth of one species affects the current state of the other species based on the logistic growth of more than two species (Modis, 2011). In recent years, applied research has frequently been conducted in the social sciences and business to analyze competitive relationships in diffusion processes.

The diffusion processes of emerging technology and new products have been well documented using the Lotka-Volterra model. For example, Kim (2010) analyzed the competitive diffusion of e-books and paper books that has occurred since the first appearance of e-books in the publishing market. Kreng \& Wang (2011) conducted a study describing the competitive relationship between LCD TVs and PDP TVs in the market and used the model to forecast a future diffusion scenario.

The Lotka-Volterra model has also been used to forecast the market demand for products. Lee, Kim, and Lee (2006) conducted research to predict the demand for WCDMA mobile phones in the market. Lakka, Varoutas, and Martakos (2013) analyzed the dynamics of the competitive diffusion of Linux, Mac OSX, and Windows in the operating systems market and estimated an equilibrium point to forecast future demands.

Studies using the Lotka-Volterra model to evaluate public policy are few yet. Watanabe, Kondo, and Nagamatsu (2003) estimated the diffusion of digital TV over time and evaluated the Japanese government's approach for switching from analog TV to digital TV. Lee, Lee, and Oh (2005) analyzed what kind of competitive relationships had emerged between KOSPI and KOSDAQ since the introduction of KOSDAQ to the Korean stock market and presented policy implications.

Several studies have applied the Lotka-Volterra model to the diffusion of the energy 
sources, mainly in the field of renewable energy. Koo (2013) forecasted the future renewable energy proportion by estimating the competitive diffusion of renewable energy and nonrenewable energy. Duan et al. (2014) treated wind energy and photovoltaic solar energy as competing species in energy ecosystems and estimated the diffusion process of each energy source by countries. Drawing on an equilibrium point analysis, they explored what kinds of policies would need to be implemented to sustain the competitiveness of each energy source.

Most studies that have used the Lotka-Volterra model have analyzed the competitive relationship between two species mainly at a fixed time point. However, Lee et al. (2005) estimated models for a series of years, using the data to describe changes in the competitive relationship between KOSPI and KOSDAQ. Our study likewise analyzes diffusion over time by exploring the competitive relationship between nuclear and nonnuclear energy in Korea as reflected in the energy policies of successive Korean governments over the course of a 30-period. The analysis of changes in the competitive relationship over time is useful to understanding the dynamics of the competitive trend from the past to the present. In particular, this study tries to explain changes in the diffusion dynamics in each government.

\section{MODEL DESCRIPTION}

The Lotka-Volterra model, first proposed by Alfred J. Lotka (1925) is a classic equation of mathematical ecology, describing the diffusion of multiple species interacting in the ecosystem (Epstein, 1997). In the ecosystem, if there are two competing species, a revised Lotka-Volterra model of simultaneous differential equations describes their relationship as follows (Modis, 1999).

$$
\begin{aligned}
& \dot{X}=\frac{d X}{d t}=a_{1} X-b_{1} X^{2}-c_{1} X Y, \\
& \dot{Y}=\frac{d Y}{d t}=a_{2} Y-b_{1} Y^{2}-c_{1} Y X
\end{aligned}
$$

where $X(t)$ and $Y(t)$ denote the populations of two species, predators and preys, at time $t$, and hence denote the adopter functions of nuclear energy and nonnuclear energy in our study; $a_{i}$ represents the parameter of natural growth effect of the own species when it is living alone; $b_{i}$ represents the parameter of inhibited growth effect by the increase of the species itself; $c_{i}$ represents the parameter of inhibited growth effect by other 
species (Modis, 1999). Equations 1 and 2 can also be presented in the form of difference equations, using the so- called discrete Lotka-Volterra model (Leslie, 1957), as follows.

$$
\begin{aligned}
& X(t+1)=\frac{\alpha_{1} X(t)}{1+\beta_{1} X(t)+\gamma_{1} Y(t)}, \\
& Y(t+1)=\frac{\alpha_{2} Y(t)}{1+\beta_{2} Y(t)+\gamma_{2} X(t)} .
\end{aligned}
$$

The relationship between the parameters of the difference equations and the differential equations can be expressed as follows (Leslie, 1957).

$$
\begin{aligned}
& a_{i}=\ln \alpha_{i}, \\
& b_{i}=\frac{\beta_{i} \ln \alpha_{i}}{\alpha_{i}-1}, \\
& c_{i}=\frac{\gamma_{i} \ln \alpha_{i}}{\alpha_{i}-1} .
\end{aligned}
$$

Once we estimate the parameter of $c_{i}$, the interaction effect of two competing species, it is possible to explain the type of the competitive relationship between two species. Modis (1999) analyzed the competitive relationship with the sign of the parameter $c_{i}$ of differential equations. Note that the sign of $\frac{\ln \alpha_{i}}{\alpha_{i}-1}$ is always positive; thus the sign of $c_{i}$ is always identical to the sign of $\gamma_{i}$ as in the equation 7. All possible combinations of signs of $c_{1}$ and $c_{2}$, or vice versa are shown in table 2 .

Table 2. Types of Competitive Relationship According to the Signs of $c_{i}$

\begin{tabular}{c|c|l|l}
\hline \multicolumn{2}{c|}{ Sign of $c_{i}$} & \multicolumn{1}{c}{ Type } & \multicolumn{1}{c}{ Explanation } \\
\hline+ & + & pure competition & Both species suffer from each other. \\
\hline+ & - & predator-prey & One species grows by preying on the other species. \\
\hline- & - & mutualism & Win-win situation occurs between both species. \\
\hline- & 0 & commensalism & $\begin{array}{l}\text { One species is not affected by the other species but helps } \\
\text { other species' growth. }\end{array}$ \\
\hline+ & 0 & amensalism & $\begin{array}{l}\text { One species is not affected by the other species but } \\
\text { interrupts other species' growth. }\end{array}$ \\
\hline 0 & 0 & neutralism & No interaction occurs between both species. \\
\hline
\end{tabular}


Values of $X$ and $Y$ satisfying both equations 8 and 9 constitute the equilibrium point. The equilibrium point derived in the context of a given policy in the present represents the threshold point that is supposed to be reached in the future (Duan et al., 2014). If there exists a stable equilibrium point of two species, self-restriction effects estimated with the parameter $b_{i}$ overwhelm the interactive activation effects estimated with the parameter $c_{i}$ and prevent the population explosion under conditions of mutualism (Epstein, 1997).

$$
\begin{aligned}
& \dot{X}=\frac{d X}{d t}=a_{1} X-b_{1} X^{2}-c_{1} X Y=0, \\
& \dot{Y}=\frac{d Y}{d t}=a_{2} Y-b_{2} Y^{2}-c_{2} Y X=0 .
\end{aligned}
$$

Values of $X$ and $Y$ satisfying both equations 8 and 9, excluding the origin, are as follows.

$$
\begin{aligned}
& X=\frac{a_{1}-c_{1} Y}{b_{1}}, \\
& Y=\frac{a_{2}-c_{2} X}{b_{2}},
\end{aligned}
$$

Note that $\frac{d X}{d t}$ tends to increase or decrease depending on the value of $X$. This can be expressed by the following equations.

$$
\begin{aligned}
& \text { If } X<\frac{a_{1}-c_{1} Y}{b_{1}}, \frac{d X}{d t}>0, \text { and } \\
& \text { if } X>\frac{a_{1}-c_{1} Y}{b_{1}}, \frac{d X}{d t}<0 .
\end{aligned}
$$

Similarly, $\frac{d Y}{d t}$ tends to increase or decrease depending on the value of $Y$. This can be expressed by the following equations . 


$$
\begin{aligned}
& \text { If } Y<\frac{a_{2}-c_{2} X}{b_{2}}, \frac{d Y}{d t}>0 \text {, and } \\
& \text { if } Y>\frac{a_{2}-c_{2} X}{b_{2}}, \frac{d Y}{d t}<0 .
\end{aligned}
$$

The presence of a stable equilibrium point can be verified quantitatively using the Lyapunov function (Khalil, 2002).

\section{EMPIRICAL ANALYSIS AND RESULTS}

\section{Data}

This study applies the Lotka-Volterra model to nuclear energy and nonnuclear energy, treating them as two competing species. We first analyze the installed capacity data of each energy source. The time period of analysis is from 1978 to 2012. Note that the first nuclear power plant in Korea started commercial operation in 1978 and that data up to 2012 are officially available.

Annual data published from the Korea Power Exchange (KPX) is used to obtain total installed power capacity and installed nuclear power capacity each year. Since nonnuclear energy includes all energy sources but nuclear energy, the installed capacity of nonnuclear energy was calculated by subtracting the installed nuclear power capacity from the total installed power capacity. Duan et al. (2014) and Valle and Furlan (2014) also used installed power capacity to conduct studies on energy diffusion.

\section{Model Estimation}

This study estimates parameters of equations 3 and 4 using the IBM SPSS Statistics 21 and the Marquardt algorithm. The results are shown in table 3.

Estimated models show high $R^{2}$ values for both nuclear energy and nonnuclear energy. $F$-statistics for model specification tests also demonstrate statistical significances for both energy types. Along with the MAPE values, all measures of goodness of fit verify that both estimated models fit real observations significantly.

Figure 1 illustrates the observed annual data of installed nuclear capacity and the annual estimates derived from application of the Lotka-Volterra model. Figure 2 illustrates the observed annual data of installed nonnuclear capacity and the annual estimates from derived from application of the Lotka-Volterra model. A solid line 
Table 3. Parameter Estimations of the Discrete Lotka-Volterra Model

\begin{tabular}{c|c|c}
\hline \multirow{2}{*}{ Parameter } & Nuclear $(i=1)$ & Non-nuclear $(i=2)$ \\
\cline { 2 - 3 } & Estimates & Estimates \\
\hline$\alpha_{i}$ & 1.22442 & 1.09634 \\
\hline$\beta_{i}$ & $3.00954 \mathrm{E}-08$ & $2.32538 \mathrm{E}-09$ \\
\hline$\gamma_{i}$ & $-6.68672 \mathrm{E}-09$ & $-3.89819 \mathrm{E}-09$ \\
\hline$R^{2}$ & 0.991 & 0.996 \\
\hline$F$ & $4058.55^{\star * *}$ & $9530.68^{\star * *}$ \\
\hline MAPE & $9.35 \%$ & $4.74 \%$ \\
\hline
\end{tabular}

$\left({ }^{\star} p<0.1,{ }^{* \star} p<0.05,{ }^{* \star *} p<0.01\right)$

represents observed data and a dotted line represents the estimated Lotka-Volterra model. The figures show that the installed capacities of both nuclear energy and nonnuclear energy have increased gradually with time.

Figure 1. Observed and Estimated Cumulative Installed Nuclear Power Capacity by Year (1978-2012)

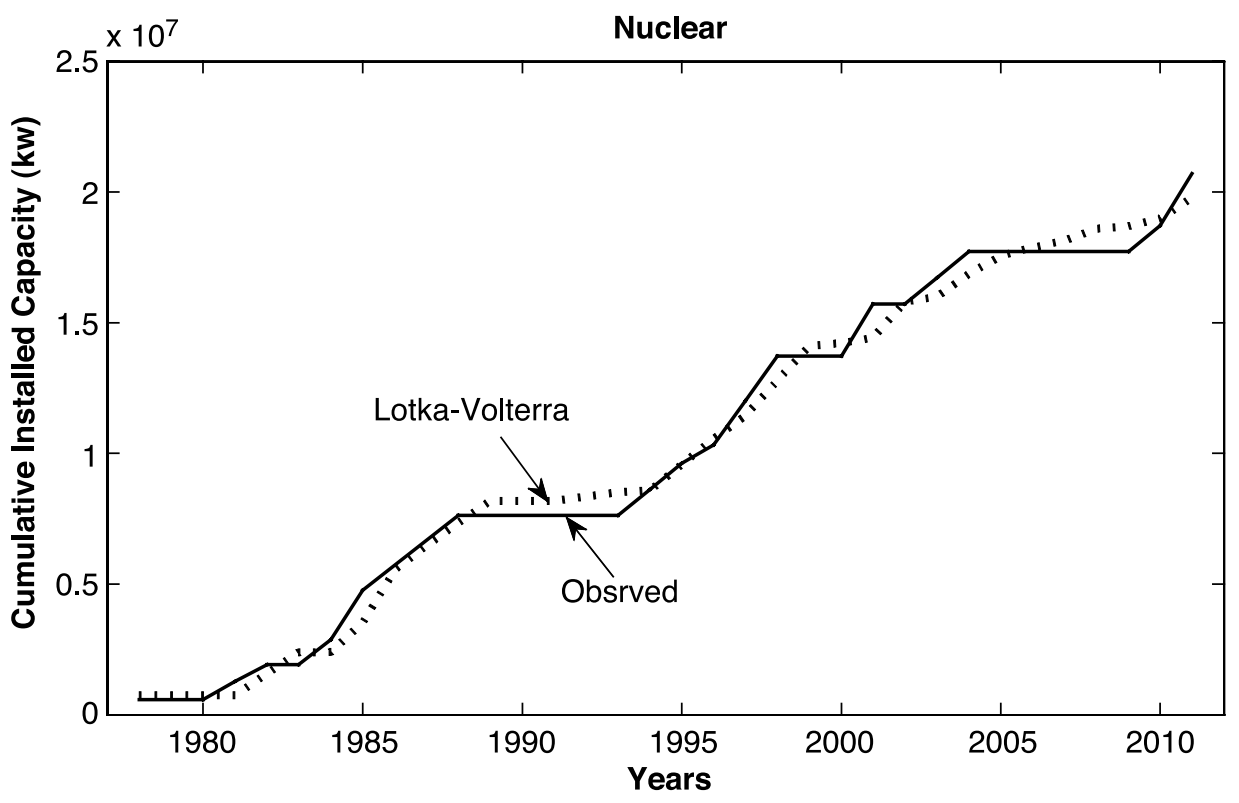


Figure 2. Observed and Estimated Cumulative Installed Nonnuclear Power Capacity by year (1978-2012)

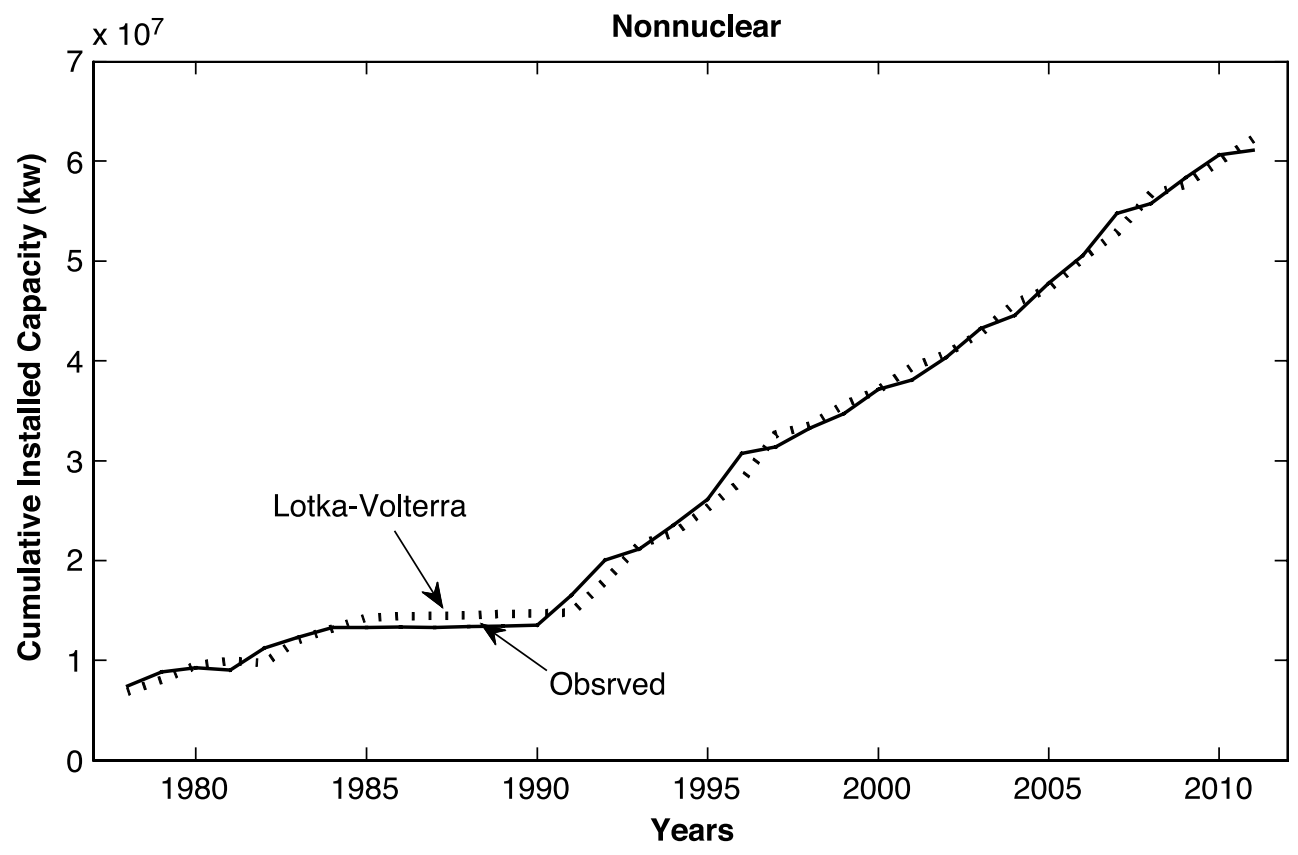

\section{Competitive Relationship Analysis}

Parameters of equations 1 and 2 can be obtained from equations 5, 6, and 7, together with estimated parameters of differential equations in table 3 . The results are shown in table 4.

As shown in table 4 , the competitive relationship between nuclear energy and nonnuclear energy can be characterized as a mutualistic one because signs of $c_{1}$ and $c_{2}$ are both negative. What this means, as shown in table 2 , is that nuclear energy and

Table 4. Parameter Estimation of Lotka-Volterra Model

\begin{tabular}{c|c|c}
\hline \multirow{2}{*}{ Parameter } & Nuclear $(i=1)$ & Nonnuclear $(i=2)$ \\
\cline { 2 - 3 } & Estimates & Estimates \\
\hline$a_{i}$ & 0.20246 & 0.09197 \\
\hline$b_{i}$ & $2.71516 \mathrm{E}-08$ & $2.22008 \mathrm{E}-09$ \\
\hline$c_{i}$ & $-6.03263 \mathrm{E}-09$ & $-3.72167 \mathrm{E}-09$ \\
\hline
\end{tabular}


Table 5. Competitive Relationship Between Nuclear and Nonnuclear Power by Year (1982-2012)

\begin{tabular}{|c|c|c|c|c|c|c|}
\hline \multirow{2}{*}{ Year } & \multirow{2}{*}{ President } & \multicolumn{2}{|c|}{ Nuclear } & \multicolumn{2}{|c|}{ Nonnuclear } & \multirow{2}{*}{$\begin{array}{l}\text { Competitive } \\
\text { Relationship }\end{array}$} \\
\hline & & Sign of $c_{i}$ & $R^{2}$ & Sign of $c_{i}$ & $R^{2}$ & \\
\hline 1982 & \multirow{6}{*}{ Chun Doo-hwan } & - & 0.583 & - & 0.833 & mutualism \\
\hline 1983 & & - & 0.899 & - & 0.954 & mutualism \\
\hline 1984 & & - & 0.778 & - & 0.937 & mutualism \\
\hline 1985 & & - & 0.884 & - & 0.959 & mutualism \\
\hline 1986 & & - & 0.930 & - & 0.922 & mutualism \\
\hline 1987 & & - & 0.962 & - & 0.922 & mutualism \\
\hline 1988 & \multirow{5}{*}{ Roh Tae-woo } & - & 0.975 & + & 0.921 & predator-prey \\
\hline 1989 & & - & 0.981 & + & 0.928 & predator-prey \\
\hline 1990 & & - & 0.984 & + & 0.933 & predator-prey \\
\hline 1991 & & - & 0.986 & + & 0.937 & predator-prey \\
\hline 1992 & & - & 0.988 & - & 0.870 & mutualism \\
\hline 1993 & \multirow{5}{*}{ Kim Young-sam } & - & 0.983 & - & 0.867 & mutualism \\
\hline 1994 & & - & 0.983 & - & 0.910 & mutualism \\
\hline 1995 & & - & 0.983 & - & 0.938 & mutualism \\
\hline 1996 & & - & 0.984 & - & 0.957 & mutualism \\
\hline 1997 & & - & 0.986 & + & 0.970 & predator-prey \\
\hline 1998 & \multirow{5}{*}{ Kim Dae-jung } & - & 0.987 & - & 0.970 & mutualism \\
\hline 1999 & & - & 0.986 & - & 0.976 & mutualism \\
\hline 2000 & & - & 0.988 & - & 0.980 & mutualism \\
\hline 2001 & & - & 0.989 & - & 0.984 & mutualism \\
\hline 2002 & & - & 0.989 & - & 0.986 & mutualism \\
\hline 2003 & \multirow{5}{*}{ Roh Moo-hyun } & - & 0.991 & - & 0.988 & mutualism \\
\hline 2004 & & - & 0.992 & - & 0.990 & mutualism \\
\hline 2005 & & - & 0.993 & - & 0.991 & mutualism \\
\hline 2006 & & - & 0.993 & - & 0.992 & mutualism \\
\hline 2007 & & - & 0.993 & - & 0.993 & mutualism \\
\hline 2008 & \multirow{5}{*}{ Lee Myung-bak } & - & 0.991 & + & 0.994 & predator-prey \\
\hline 2009 & & - & 0.990 & - & 0.994 & mutualism \\
\hline 2010 & & - & 0.990 & - & 0.995 & mutualism \\
\hline 2011 & & - & 0.991 & - & 0.996 & mutualism \\
\hline 2012 & & - & 0.991 & - & 0.996 & mutualism \\
\hline
\end{tabular}


nonnuclear energy promoted the proliferation of each other in the diffusion process.

The form of competitive relationship that existed between nuclear energy and nonnuclear energy as reflected in Korean energy policy from 1982 to 2102 has been determined by estimating $c_{1}$ and $c_{2}$ each year. The results are summarized in table 5 . Estimated models between 1978 and 1981 turned out to be insignificant with respect to low $R^{2}$ values, and thus results are not reported for those years.

According to table 5, mutualism has generally characterized energy diffusion in Korea, which means that nuclear energy and nonnuclear energy mostly stood in winwin relationship, promoting the proliferation of each other in the diffusion process.

Jin (2009) and Choi et al. (2009) claimed that the nuclear energy policy of Korea shows path-dependent characteristics. Joo (2011) also argued that in Korea, nuclear energy has maintained a gradual expansion based on path dependency with the support from former governments. In table 5, signs of $c_{i}$ of nuclear energy have remained negative since 1982. In epidemic terms, negative $c_{i}$ implies a competitive advantage of the corresponding species. Thus we conclude that nuclear energy in Korea has maintained its competitiveness since 1982. In general, no radical change in a sign of $c_{i}$ indicates a path-dependent characteristic.

For the years between 1988 and 1991 and then again in 1997 and 2008 during which the relationship between nuclear and nonnuclear energy took the form of predatorprey, we conclude that nuclear energy as a predator inhibited the diffusion of nonnuclear energy as a prey in the diffusion process. During the four years from 1988 to 1991 the Roh Tae-woo government was in office, the Kim Young-sam government was in power in 1997, and the Lee Myung-bak government was in power in 2008. In other words, right after the mutualism the characterized the Chun Doo-hwan government's energy policy, nonnuclear energy lost its competitive advantage in Roh Tae-woo government. But this predator-prey relationship was replaced by mutualism at the end of Roh Tae-woo government and mutualism relationship generally prevailed until through the Lee Myung-bak government, except for short sporadic periods in which a predator-prey relationship reemerged in 1997 and 2008.

The reason why a predator-prey relationship prevailed from 1988 to 1991 under the Roh Tae-woo government could be explained as follows. In the early 1980s, annual economic growth rates of Korea were around $10 \%$, which led to an explosion of energy consumption. The Chun Doo-hwan government faced fast-growing energy demands, and it was hard to meet the surging power demand with existing coal and hydroelectric power plants. Therefore, after launching the first commercial nuclear power plant in 1978, Chun Doo-hwan government constructed many more nuclear power plants but fewer nonnuclear energy facilities. There were limited national resources for expanding energy facilities, and the government at the time choose to use those limited resources 
to construct more nuclear power plants, which resulted a slow down in the diffusion of nonnuclear energy. After the Chernobyl accident in 1986, fewer new nuclear power plants were constructed in Korea, as was the case in most developed countries. However, existing projects for nuclear power plants under construction were continued, and those plants began commercial operations under the Roh Tae-woo government.

In later 1980s and early 1990s, the nuclear energy policy of Roh Tae-woo government was strongly impacted by the Joint Declaration on the Denuclearization of the Korean Peninsulas and citizens' active antinuclear movements after democratization. During those years, no new plans were developed to build new nuclear power plants, and therefore the overall diffusion curve began to take a more mutualistic form at the end of Roh Tae-woo government. Since then, the competitive relationship between nuclear energy and nonnuclear energy has remained roughly a mutualistic one. In mid 1990s, however, the construction of new nuclear power plants resumed after the electric power reserve rate went down below $5 \%$ and new nonnuclear power plants continued to built as well. This may explain the sporadic appearance of a predator-prey relationship in 1997 and 2008.

\section{Equilibrium Analysis and Numerical Simulation}

The equilibrium points of nuclear energy and nonnuclear energy were estimated using the estimated parameters and equations 10 and 11. An equilibrium of nuclear energy and nonnuclear energy in 2012 is illustrated in figure 3.

Using equations $12,13,14$, and 15 , we represent changes in the diffusion process of nuclear energy and nonnuclear energy in areas A, B, C, and D in figure 3. Equations 12 and 14 have been applied to area A so as to show the increase of both nuclear energy and nonnuclear energy over time. Equations 12 and 15 have been applied to area B to show the increase of nuclear energy and the decrease of nonnuclear energy over time. Equations 13 and 14 have been applied to area $\mathrm{C}$ to indicate the decrease of nuclear energy and increase of nonnuclear energy over time. Equations 13 and 15 have been applied to show a decrease in both nuclear and nonnuclear energy over time. Therefore, nuclear energy and nonnuclear energy will converge to the equilibrium point $\mathrm{E}$ with zero growth rate. In this case, the installed capacity of nuclear energy converges at 26,550,346 kilowatts and the installed capacity of nonnuclear energy converges at $85,935,843$ kilowatts. In general, this equilibrium point is affected by past growth patterns, current policy environment, changes in policy, and technological progresses (Duan et al., 2014).

Using the estimated equilibrium point, we conducted a numerical simulation to forecast the proportion of installed capacity of nuclear energy in 2030 under the 
Figure 3. Equilibrium Between Nuclear and Nonnuclear Power in 2012

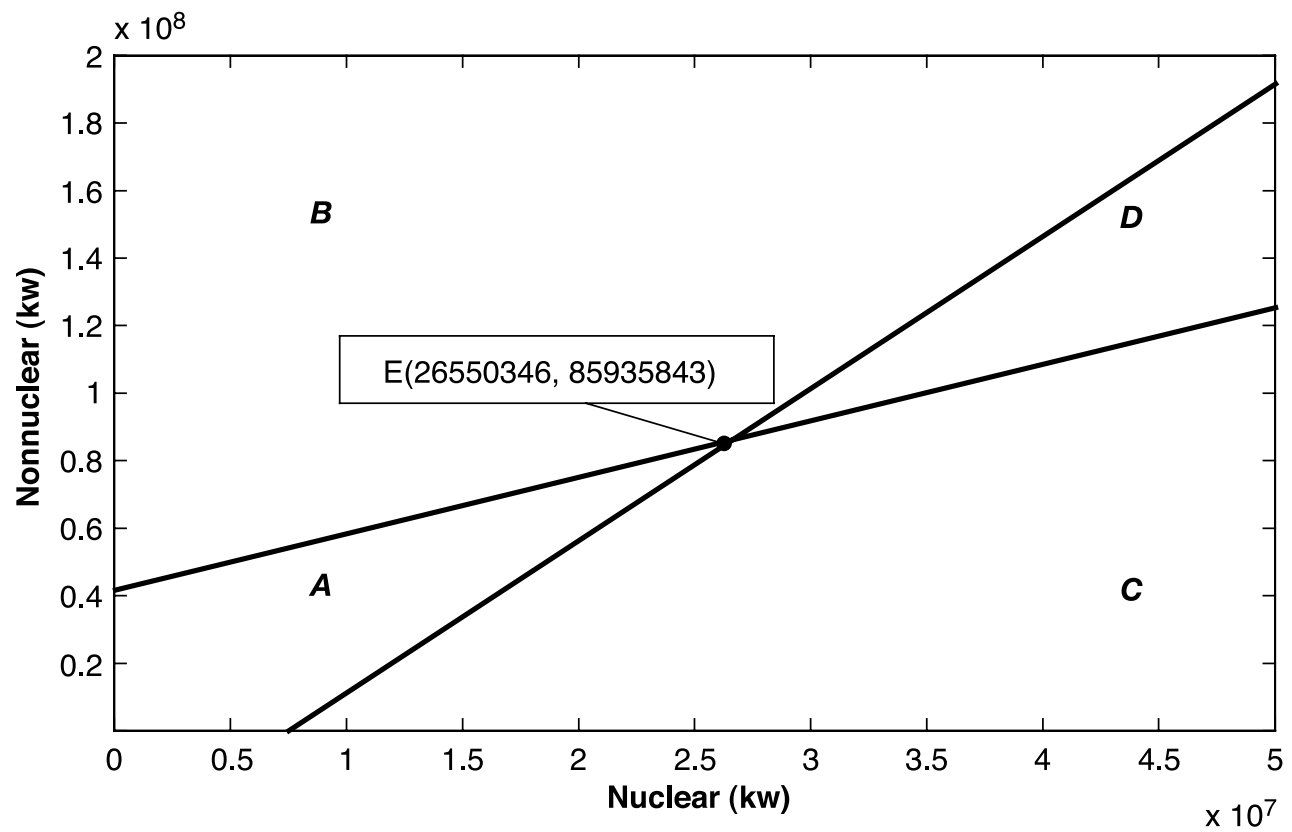

Figure 4. Forecasting Nuclear Power Proportions Using Numerical Simulation by Year (2013-2030)

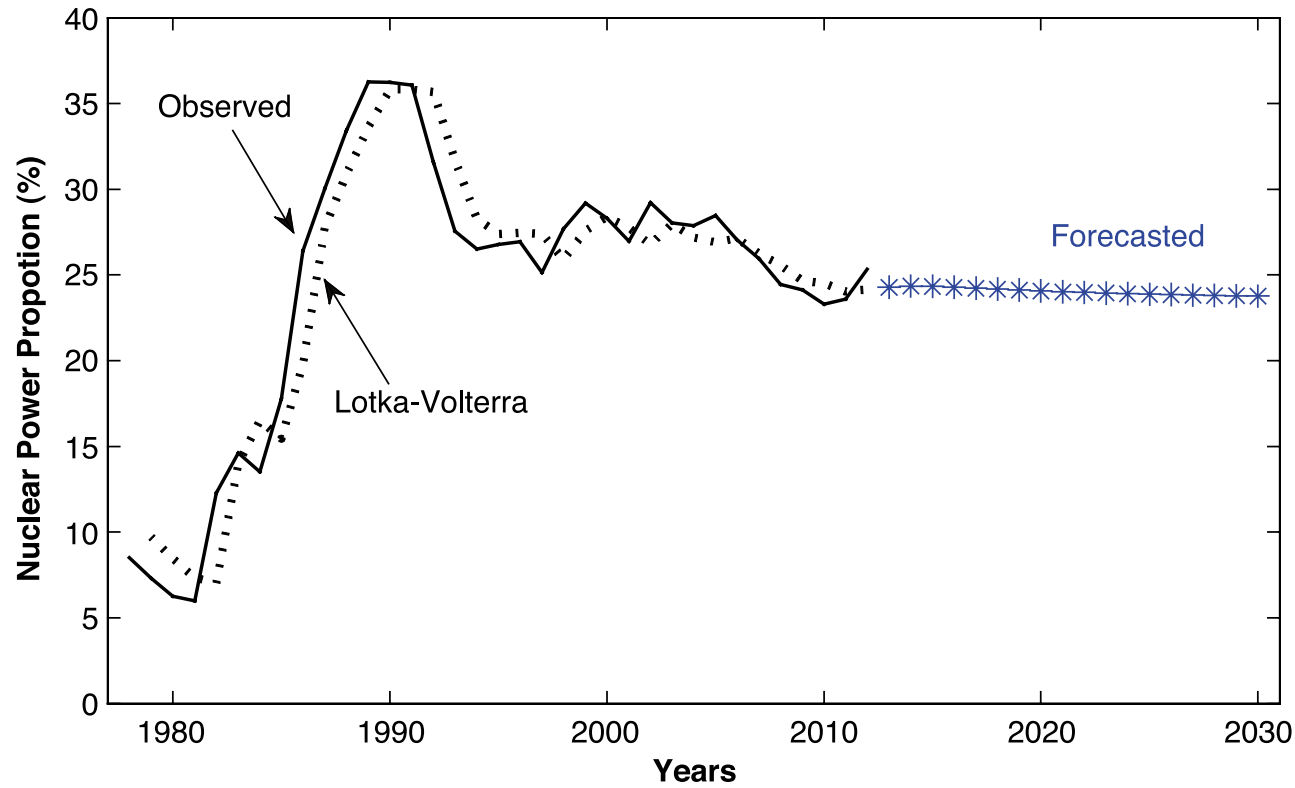


assumption that current competitive relationship will be maintained. We used the Runge-Kutta 4th order method in Matlab R2013b with a one-year time interval for integration up to year 2030. After forecasting the installed capacity by each year, we calculated the proportion of nuclear energy. The results are shown in figure 4.

In figure 4, a solid line represents observed data, a dotted line represents the estimated Lotka-Volterra model, and the asterisks on the right side represent the forecasted proportion of nuclear energy from a numerical simulation. As shown in figure 5 , the proportion of nuclear energy out of the total energy sources in the future is expected to decrease slightly.

The initial proportion of nuclear energy in 1978 was $8.5 \%$. The proportion soared rapidly after early 1980s, reaching $36.3 \%$ in 1989, the highest point ever. After 1989, the proportion of nuclear energy decreased and stabilized around $25 \%$ to $30 \%$. The proportion of nuclear energy in 2012 was $25.3 \%$, and a gradual downward trend is expected over time. In 2030, the proportion of nuclear energy is forecasted to be $23.8 \%$, which will converge to $23.6 \%$ at the equilibrium point with time. In other words, the stably maintained ratio of around $25 \%$ since the mid-1990s will not change significantly in the future.

Note that in the cabinet meeting of January 14, 2014, the Korean government confirmed the second national energy plan to increase the proportion of nuclear power generation to $29 \%$ by 2035 . This figure is about $5 \%$ higher than the forecasted proportion at the equilibrium point under the assumption that the current competitive relationship persists.

\section{CONCLUSION}

This study deals with energy diffusion in Korea since the advent of nuclear power generation in 1978. We have treated the competitive relationship between nuclear energy and nonnuclear energy in the diffusion process as a competitive ecosystem and have analyzed it using the Lotka-Volterra model. We have also used the model to generate estimations that capture the relationship between the two forms of energy as manifested in the energy policy of successive Korean governments, and we have further estimated the equilibrium point and used that to forecast the future diffusion scenario under the assumption that the current competitive relationship will be maintained.

Our results show a change in the competitive relationship between nuclear energy and nonnuclear energy over time. Under the Chun Doo-hwan government from 1982 to1987, the competitive relationship between nuclear energy and nonnuclear energy 
was characterized by mutualism. However, under the Roh Tae-woo government from 1988 to 1992, the competitive relationship changed from one of mutualism to one of predator-prey. In other words, right after the mutualism seen under the Chun Doohwan government, nuclear energy achieved dominance over nonnuclear energy during Roh Tae-woo's administration. But this predator-prey relationship was replaced by mutualism again at the end of Roh Tae-woo's presidency, and mutualism relationship remained the norm until the end of the Lee Myung-bak government, except for short periods, in 1997 and 2008, when a predator-prey relationship emerged. These trends of competitive relationship imply changes in the energy policy basis of each government.

This study can be characterized as an exploratory in nature. We adopted a mathematical approach of nonlinear dynamics to describe the diffusion of nuclear energy and nonnuclear energy in a competitive relationship. Utilizing a mathematical ecology model, the Lotka-Volterra model, this study has tried to introduce a relatively new methodology for policy evaluations. In addition, this study has used a numerical simulation in forecasting, which is rarely employed in the field of policy studies.

The quantitative analysis using mathematical models like ours does have methodological weaknesses. Typically, mathematical models tend to overly simplify the policy situation and utilize very limited information and thus do not have as many implications for policy making as other models. However, as Makridakis and Hibon (2000) demonstrated, the forecasting accuracy of complex or sophisticated models is not always higher than simple ones. Also, complicated forecasting models have methodological shortcomings, such as insufficient data. For these reasons, simplified diffusion models based on a logistic growth equation are used widely for analyzing the energy sector. As Kim (2012) pointed out, the available data is a very important consideration in choosing an appropriate methodology in policy evaluation. This study is based on the data of installed capacities of energy facilities and does not consider qualitative data and the interaction of other variables influencing related policies. Therefore, research conducted in the future should seek to use both qualitative methodologies and mathematical models to compensate for methodological shortcomings.

In addition, this study cannot predict a change in competitive relationships and equilibrium points that are possibly caused by technological innovations and the rapid diffusion of new energy sources, since the forecasting was conducted under the assumption that the current competitive relationship would last. This means that we cannot guarantee that the result of our forecasting will be highly accurate in the long term, but it is still be powerful in the short and medium term. This is the main shortcoming of almost every diffusion model based on a logistic growth equation. An agent-based simulation may be alternative methodology for predicting radical changes.

Despite these methodological shortcomings, this study effectively shows the 
dynamics of energy diffusion and suggests a new direction for analyzing the competitive relationship between competing policies in a policy ecosystem.

\section{REFERENCES}

Adamantiades, A., \& Kessides, I. 2009. Nuclear power for sustainable development: Current status and future prospects. Energy Policy, 37(12): 5149-5166.

Choi, S., Jun, E., Hwang, I., Starz, A., Mazour, T., \& Chang, S. 2009. Fourteen lessons learned from the successful nuclear power program of the Republic of Korea. Energy Policy, 37(12): 5494-5508.

Duan, H., Zhu, L., \& Fan, Y. 2014. A cross-country study on the relationship between diffusion of wind and photovoltaic solar energy. Technological Forecasting \& Social Change, 83: 156-169.

Epstein, M. J. 1997. Nonlinear dynamics, mathematical biology, and social science. Santa Fe, NM: Addison-Wesley.

Freedman, H. I., 1980. Deterministic mathematical models in population ecology. New York: Marcel Dekker.

Hoppensteadt, F. 2006. Predator-prey model. Scholarpedia, 1(10): 1563.

Furlan, C., Guidolin, M., \& Guseo, R. 2014. Are there any effects of [the] Fukushima accident on the diffusion of nuclear energy? Paper presented at the SIS (Italian Statistical Society) 2014 conference.

Guidolin, M., \& Mortarino, C. 2010. Cross-country diffusion of photovoltaic systems: Modeling choices and forecasts for national adoption patterns. Technological Forecasting \& Social Change, 77(2): 279-296.

Guidolin, M., \& Guseo, R. 2012. A nuclear power renaissance? Technological Forecasting \& Social Change, 79(9):1746-1760.

Guseo, R., \& Guidolin, M. 2009. Modeling a dynamic market potential: A class of automata networks for diffusion of innovations. Technological Forecasting \& Social Change, 76(6): 806-820.

Harijan, K., Uqaili, M. A., Memon, M., Mirza, \& U. K. 2011. Forecasting the diffusion of wind power in Pakistan. Energy, 36(10): 6068-6073.

Hwang, B. 2011. A study on the energy society prospectus through building the system dynamics model. KISTEP (Korea Institute of S\&T Evaluation and Planning) Report.

Hwang, S., Won, J., \& Kim, J. 2005. Diffusion state estimation of new and renewable energy using diffusion model. Proceedings of the Korean Institute of Electrical Engineers. 2005(10): 320-322. 
Joo, S., 2011. Study on the change of nuclear policy in Korea: Focusing on historical institution and actor. PhD thesis, Catholic University of Korea.

Jin, S. H. 2009. A study of the path dependency of Korean nuclear energy policy. Korea Association for Policy Studies, 18(4): 123-145.

Kessides, I. 2010. Nuclear power: Understanding the economic risks and uncertainties. Energy Policy, 38(8): 3849-3864.

Koo, S., Lee, D., \& Kim, T. 2014. Forecasting the diffusion process and the required scale of R\&D investment of renewable energy in Korea using the comparative analogy method. Journal of the Korean Institute of Industrial Engineers, 40(3): 333-341.

Koplow, D., 2011. Nuclear power: Still not viable without subsidies. Cambridge, MA: UCS Publications.

Khalil, H. K. 2002. Nonlinear Systems. 3rd ed. Upper Saddle River, NJ: Prentice Hall.

Kreng, B. V., \& Wang, T. H. 2011. The competition and equilibrium analysis of LCD TV and PDP TV. Technological Forecasting \& Social Change, 78(3): 448-457.

Kim, K. 2010. An analysis of competition patterns between paper books and e-books using the Lotka-Volterra model. Journal of the Korea Academia-Industrial Cooperation Society, 11(12): 4766-4773.

Lakka, S., Michalakelis, C., Varoutas, D., \& Martakos, D. 2013. Competitive dynamics in the operating systems market: Modeling and policy implications. Technological Forecasting \& Social Change, 80(1): 88-105.

Lee, S., Lee D., \& Oh, H. 2005. Technological forecasting at the Korean stock market: A dynamic competition analysis using Lotka?Volterra model. Technological Forecasting \& Social Change, 72(8): 1044-1057.

Lee, S. H., Kim, J. B., \& Lee, B. C. 2006. Forecasting the demand of WCDMA mobile phones. Journal of the Korea Society for Simulation, 15(4): 153-160.

Lee, S. R. 2001. Nuclear energy policy and the dilemma of participatory democracy in Korea. Public Policy Review, 15(2): 125-144.

Leslie, P. H. 1957. A stochastic model for studying the properties of certain biological systems by numerical methods. Biometrika, 45(1), 16-31.

Lotka, A. J. 1925. Elements of physical biology. Baltimore, MD: Williams and Wilkins.

Makridakis, S., \& Hibon, M. 2000. The M3-competition: Results, conclusions and implications. International Journal of Forecasting, 16(4): 451-476.

Marchetti, C., 1981. Society as a learning system: Discovery, invention, and innovation cycles revisited. Technological Forecasting \& Social Change, 18(4): 267-282.

Marchetti, C., 1985. Nuclear plants and nuclear niches: On the generation of nuclear energy during the last twenty years. Nuclear Science and Engineering, 90(4): 521-526. 
Modis, T. 1999. Technological forecasting at the stock market. Technological Forecasting \& Social Change, 62(3): 173-202.

Modis, T. 2011. US Nobel laureates: Logistic growth versus Volterra-Lotka. Technological Forecasting \& Social Change, 78(4): 559-564.

Pandey, R. 2002. Energy policy modeling: Agenda for developing countries. Energy Policy, 30(2): 97-106.

Schaffer, L.M., \& Bernauer, T. 2014. Explaining government choices for promoting renewable energy. Energy Policy, 68: 15-27.

Toth, F. L., \& Rogner, H.-H. 2006. Oil and nuclear power: Past, present, and future. Energy Economics, 28(1): 1-25.

Valle, A. D., \& Furlan, C. 2011. Forecasting accuracy of wind power technology diffusion models across countries. International Journal of Forecasting, 27(2): 592-601.

Valle, A. D., \& Furlan, C. 2014. Diffusion of nuclear energy in some developing countries. Technological Forecasting \& Social Change, 81: 143-153.

Van der Heiden, N., \& Strebel, F. 2012. What about non-diffusion? The effect of competitiveness in policy-comparative diffusion research. Policy Sciences, 45(4): 345-358.

Watanabe, C., Kondo, R., \& Nagamatsu, A. 2003. Policy options for the diffusion orbit of competitive innovations?an application of Lotka-Volterra equations to Japan's transition from analog to digital TV broadcasting. Technovation, 23(5): 437-445.

Yoon, Y. C., \& Bae, E. H. 2008. The relationship between a focal organization and its task-related organizations: A focus on the case of nuclear power plant. Korean Journal of Policy Administration, 46(4): 145-174. 